\title{
$\mathrm{CoSe}_{2} / \mathrm{Co}$ nanoheteroparticles embedded in $\mathrm{Co}, \mathrm{N}$ co-doped carbon
} nanopolyhedra/nanotubes as an efficient oxygen bifunctional electrocatalyst for

\section{Zn-air batteriest}

\author{
Jizhao Zou ${ }^{a}$, Qi $\quad$ Luo $^{a}$, Hongliang $\quad$ Wu ${ }^{* a}$, Shiyu Liu ${ }^{a}$, Tongbin $\quad$ Lan $^{a}$, Yuechao \\ Yao $^{a}$, Muhammad Aurang Zeb Gul Sial ${ }^{a}$, Fenglin Zhao ${ }^{a}$, Qi Zhang ${ }^{b}$ and Xierong Zeng ${ }^{a}$ \\ ${ }^{a}$ Shenzhen Key Laboratory of Special Functional Materials, Shenzhen Engineering Laboratory for Advance Technology of \\ Ceramics, College of Materials Science and Engineering, Shenzhen University, Shenzhen, 518060, P. R. China. \\ E-mail: whl@szu.edu.cn \\ ${ }^{b}$ School of Aerospace, Transport and Manufacturing, Cranfield University, Cranfield, Bedfordshire MK43 OAL, UK
}

\begin{abstract}
Transition metal selenide-based materials have been demonstrated as promising electrocatalysts for the oxygen reduction reaction (ORR) and oxygen evolution reaction (OER), yet the actual design of a highly efficient and stable electro-catalyst based on these materials still remains a long and arduous challenge. Herein, a predesigned hybrid $\mathrm{Zn} / \mathrm{Co}$ zeolitic imidazole framework was used to fabricate $\mathrm{CoSe}_{2} / \mathrm{Co}$ nanoheteroparticles embedded within hierarchically porous $\mathrm{Co}, \mathrm{N}$ co-doped carbonnanopolyhedra/nanotubes ( $\mathrm{CoSe}_{2} / \mathrm{Co} @ \mathrm{NC}$ CNTs) through a facile approach involving controlled carbonization and selenization procedures. As expected, the optimized $\mathrm{CoSe}_{2} / \mathrm{Co} @ \mathrm{NC}-\mathrm{CNT}-1$ displayed outstanding electrocatalytic performance for the ORR and OER, with an onset potential of $0.95 \mathrm{~V} v s$. RHE, a half-wave potential of $0.84 \mathrm{~V} v s$. RHE for ORR, and a potential of $1.69 \mathrm{~V} v s$. RHE for OER at $10 \mathrm{~mA} \mathrm{~cm}^{-2}$. It also exhibited excellent long-term stability and methanol resistance ability, which were superior to commercial $\mathrm{IrO}_{2}$ and the commercial $20 \mathrm{wt} \% \mathrm{Pt} / \mathrm{C}$ catalyst. Notably, the assembled Zn-air battery with $\mathrm{CoSe}_{2} / \mathrm{Co} @ \mathrm{NC}-\mathrm{CNT}-1$ showed a low charge-discharge voltage gap $\left(0.696 \mathrm{~V}\right.$ at $\left.10 \mathrm{~mA} \mathrm{~cm}^{-2}\right)$ and a high peak power density $\left(100.28 \mathrm{~mW} \mathrm{~cm}^{-2}\right)$ with long-term cycling stability. These superior performances can be ascribed to the synergistic effects of the highly active $\mathrm{CoSe}_{2} / \mathrm{Co}$ nanoheterostructure, hierarchically porous structure with a large surface area, high electrical conductivity and uniform doping of the Co and N.
\end{abstract}




\section{Introduction}

On account of the increasingly serious environmental pollution globally, the replacement of traditional energy has become cumulatively more essential today. Relatively, electricity has been ubiquitously used as clean and environmentally friendly energy in our daily lives, and the demands for efficient energy conversion and storage have dramatically increased. $\frac{1,2}{}$ In this case, fuel cells and metal-air batteries are gaining more and more attention among various energy devices because of their cleanness, high efficiency and environmental benignity. ${ }^{3,4}$ In these energy conversion devices, the oxygen reduction reaction (ORR) and oxygen evolution reaction (OER) are two significantly electrocatalytic reactions but they suffer from sluggish kinetics, which limit their commercialization, and therefore there is a need to find a new kind of low-cost and highly active electrocatalysts. ${ }^{5.6}$ Until now, Pt, Pt-based and $\mathrm{IrO}_{2}, \mathrm{IrO}_{2}$-based catalysts are still the best and most universal electrocatalysts for the ORR and OER. However, there are many existing problems with Pt-based catalysts, such as their high price, source shortage and limited stability. $\frac{7-9}{}$ There is thus an urgent search for economical, abundant and highly active non-precious catalysts.

Among the many investigations on non-precious metal-based electrocatalysts, a lot of attention has been concentrated on developing transition-metal oxides/chalcogenides $\left(\mathrm{M}_{x} \mathrm{O}_{y}\right.$, $\mathrm{M}_{x} \mathrm{~S}_{y}$ and $\mathrm{M}_{x} \mathrm{Se}_{y}$, etc.) due to their relatively low cost and expected long-term stability..$^{10-}$ 14 Among these, $\mathrm{CoSe}_{2}$, a kind of 3D transition metal chalcogenide, has demonstrated promise to potentially replace Pt-based catalysts. $\frac{15,16}{}$ However, pure $\mathrm{CoSe}_{2}$ still suffers from an intrinsic deficiency in terms of its low electron-transfer efficiency due to its low exposure of active sites and poor conductivity, making the electrocatalytic performance of $\mathrm{CoSe}_{2}$ still far less than expected. $\cdot \frac{17,18}{}$ Therefore, it is a huge challenge to prepare $\mathrm{CoSe}_{2}$ catalysts with more exposed active sites and enhanced charge-transfer efficiency.

Recent studies have shown that heterostructures consisting of two constituents are beneficial for increasing the active sites and improving the electrocatalytic performance. Most studies have been focused on either the construction of heterostructures with noble metals or metal/metal and metal/metallic oxide systems. ${ }^{19,20}$ For instance, Chen ${ }^{21,22}$ produced AgPd/rGO catalysts and $\mathrm{Pd}_{72} \mathrm{Ce}_{28} / \mathrm{C}$ catalysts to enhance the electrocatalytic activity for the formate oxidation reaction, and through DFT studies, the relative crystallographic planes were verified to contribute to the electrocatalytic activity. However, study into metal/metallic selenide 
heteroparticles remains quite rare and thus meaningful. Furthermore, loading active materials with a functional carbon matrix has been proven to be an effective means to improve the electrocatalytic performance of ORR and OER catalysts, $\stackrel{23-25}{2}$ in which the following factors are recognized to have an important role: (1) a high surface area with a hierarchical pore structure, which shortens the free diffusion path lengths of $\mathrm{O}_{2}$ and the electrolyte to the catalytic active sites, $\frac{26}{2}$ (2) a uniform decoration of heteroatoms (B, P, N, Co, Fe, etc.), which can usually modify the electronic properties and increase the structural and atomic defects, thus further enhancing the electrocatalytic performance of the catalysts, $\stackrel{27,28}{2}$ (3) a high density of valid active sites, as provided by $\mathrm{M}-\mathrm{N}_{x} / \mathrm{C}$, for example, where the involvement of the $\mathrm{Co}-\mathrm{N}_{x}$ moiety can effectively improve the electrocatalytic activity; $\underline{29}$ (4) high electrical conductivity, which can be enhanced by the incorporation of graphitized carbon and/or carbon nanotubes (CNTs), which are usually formed via catalysis over Fe, Co, etc ${ }^{30}$. Nevertheless, the realization of these strategies usually involves multi-step procedures, toxic reactants and rigorous experimental conditions. In this regard, discovering a universal and controllable way to combine transition metal materials with the multifunctional carbon skeleton is still quite desirable and challenging.

Metal-organic frameworks (MOFs), a kind of porous crystalline material that is constructed of metal units and organic ligands, have attracted tremendous attention in functional applications due to their extremely high surface area, variable pore structure and facile synthesis. $\frac{31-33}{2}$ The well-organized MOFs have been demonstrated as excellent precursors or sacrificial templates to prepare multifunctional carbon materials via a facile carbonization. $\frac{34}{}$ ${ }^{36}$ In particular, zeolite imidazole frameworks (ZIFs), a subclass of MOFs that are constituted by bridging zinc or cobalt ions and nitrogen-rich imidazolate linkers within polyhedral frameworks, have been utilized as ideal precursors to prepare N-doped or graphitized carbonbased nanocomposites for energy storage and conversion applications. $\underline{29,37}$

Inspired by the above, in this work, we selected hybrid $\mathrm{Zn}$ and Co bimetallic zeolitic imidazole frameworks ( $\mathrm{Zn} / \mathrm{Co}-\mathrm{ZIFs})$ as the precursor to prepare hybrid electrocatalysts composed of $\mathrm{CoSe}_{2} / \mathrm{Co}$ heterostructures and $\mathrm{Co}, \mathrm{N}$ co-doped porous carbon nanopolyhedra/nanotubes through a facile and controllable calcination-selenization strategy. The Co ions within the synthesized ZIF precursor were first reduced to metallic cobalt and then further converted to $\mathrm{CoSe}_{2} / \mathrm{Co}$ nanoheteroparticles in the subsequent reaction with selenium powder. Meanwhile, the organic ligands were in situ carbonized to a nitrogen-doped carbon matrix with high porosity and high electrical conductivity. The $\mathrm{CoSe}_{2} / \mathrm{Co}$ nanoheteroparticles were uniformly dispersed in the carbon matrix, which had a strong and stable interfacial contact with the $\mathrm{CoSe}_{2} / \mathrm{Co}$ nanoheteroparticles, significantly enhancing the mass transfer and the 
exposure of active sites. The effects of selenization and the $\mathrm{Zn}^{2+} / \mathrm{Co}^{2+}$ molar ratios on the microstructure, composition and electrocatalytic activity were systematically studied.

As expected, the as-prepared hybrid electrocatalysts showed excellent electrocatalytic activity in alkaline media, and their stability as well as methanol tolerance were superior to a commercial Pt/C catalyst.

\section{Results and discussion}

The strategy to synthesize $\mathrm{CoSe}_{2} / \mathrm{Co}$-embedded $\mathrm{Co}$, N-doped carbon nanopolyhedra/nanotubes involved three steps, as illustrated in Fig. 1. First, the hybrid Zn/Co-ZIFs with varied molar ratios of $\mathrm{Zn}^{2+} / \mathrm{Co}^{2+}$ were synthesized via the magnetically-stirred co-precipitation reaction of $\mathrm{Zn}\left(\mathrm{NO}_{3}\right)_{2}$ and $\mathrm{Co}\left(\mathrm{NO}_{3}\right)_{2}$ with 2-methylimidazole in methanol solution. Afterwards, the $\mathrm{Zn} / \mathrm{Co}-$ ZIF precipitates were separated by centrifugation and further carbonized at $800{ }^{\circ} \mathrm{C}$ under a $\mathrm{H}_{2} / \mathrm{Ar}$ atmosphere to obtain $\mathrm{Co}, \mathrm{N}$ co-doped porous carbon nanopolyhedra/nanotubes (labelled Co@NC-CNT- $x$, where $x$ indicates that the sample was derived from the corresponding Zn/CoZIFs with a $\mathrm{Zn}^{2+} / \mathrm{Co}^{2+}$ molar ratio value of $x$ ). It should be noted that the Co@NC-CNT- $x$ was strategically prepared to combine both the advantages of the Zn-ZIF-derived and Co-ZIFderived carbon matrix, such as a high porosity with a large surface area and uniformly dispersed $\mathrm{N}$ species from the Zn-ZIF-derived carbon, a highly graphitized carbon structure, highly conductive CNTs and an active $\mathrm{Co}-\mathrm{N}_{x}$ moiety from the Co-ZIF-derived carbon, with all these species conducive for a highly efficient oxygen reduction reaction. $\frac{29,38,39}{}$ Finally, a thermal selenization procedure was performed to convert the Co metal into heterostructured $\mathrm{CoSe}_{2} / \mathrm{Co}$ nanoparticles embedded within the highly porous Co, $\mathrm{N}$ co-doped carbon nanopolyhedra/nanotubes.

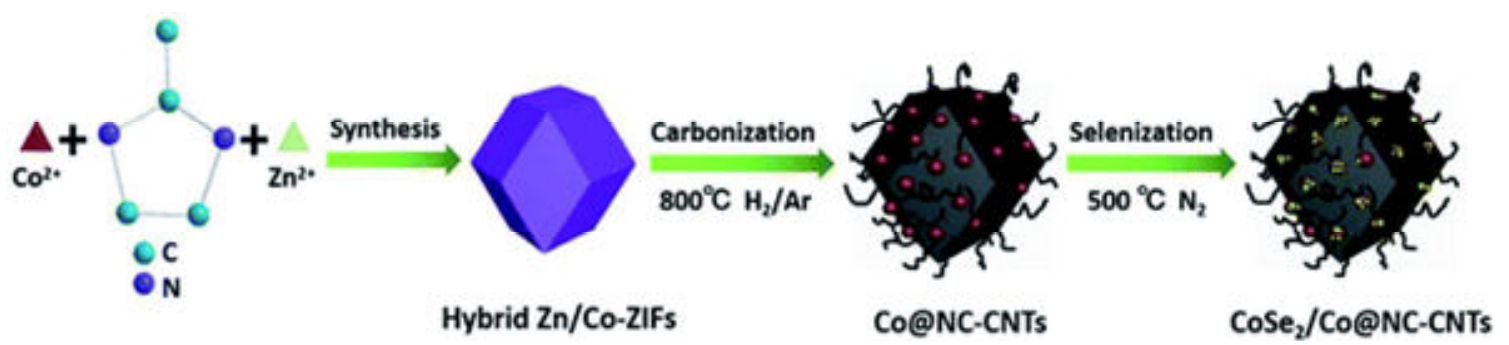

Fig. 1 Schematic illustration of the synthesis procedures of $\mathrm{CoSe}_{2} / \mathrm{Co} @ \mathrm{NC}-\mathrm{CNTs}$.

The morphology and further detailed microstructure of the as-prepared samples were investigated by scanning electron microscopy (SEM) and transmission electron microscopy (TEM). The crystalline features and composition were identified by powder X-ray diffraction (XRD). As shown in Fig. 2a and S2a-c, t the as-synthesized Zn/Co-ZIF nanoparticles showed a similar rhombic polyhedral shape with smooth surfaces and an increasing particle size (300- 
$500 \mathrm{~nm}$ ) with the molar ratio of $\mathrm{Zn}^{2+} / \mathrm{Co}^{2+}$ increasing. After carbonization, the $\mathrm{Zn} / \mathrm{Co}-\mathrm{ZIFs}$ were transformed into porous $\mathrm{Co}, \mathrm{N}$ co-doped carbon nanopolyhedra/nanotubes. As exhibited in Fig. S1 and S2d-f, the XRD patterns of Co@NC-CNT- $x$ corresponded well with those of the standard Co (PDF\#15-0806), and the diffraction peaks of Co phase became more obvious with the Co content increasing. Furthermore, no peak of $\mathrm{Zn}$ was visible, indicating the complete evaporation of $\mathrm{Zn}$ metal at such a high temperature. Compared to the original $\mathrm{Zn} / \mathrm{Co}-\mathrm{ZIFs}$, the ZIF-derived carbon particle size was decreased and the polyhedral structure was gradually unable to be maintained with the increase in the Co ratio, resulting from the degradation of organic linkers and the formation of more carbon nanotubes catalyzed from Co nanoparticles under high temperature treatment. After selenization with sufficient Se powder, some of the Co nanoparticles were transformed into $\mathrm{CoSe}_{2}$. As exhibited in Fig. 3a, the characteristic peaks of $\mathrm{CoSe}_{2} / \mathrm{Co} @ \mathrm{NC}-\mathrm{CNT}-x$ corresponded well with those of standard $\mathrm{CoSe}_{2}$ (PDF\#53-0449) and Co (PDF\#15-0806). Scanning electron microscopy (SEM) indicated that the larger particles $\left(\mathrm{CoSe}_{2} / \mathrm{Co}\right)$ were distributed on the surface of $\mathrm{CoSe}_{2} / \mathrm{Co} @ \mathrm{NC}-\mathrm{CNT}$ s compared to with the Co@NC-CNTs (Fig. 2c-f). Detailed transmission electron microscopy (TEM) studies, taking $\mathrm{CoSe}_{2} / \mathrm{Co} @ \mathrm{NC}-\mathrm{CNT}-1$ as an example, revealed that the carbon nanopolyhedra were embedded with a large number of well-dispersed $\mathrm{CoSe}_{2} / \mathrm{Co}$ nanoparticles and highly porous textures existed throughout the whole particles (Fig. $2 g$ and $h$ ). The carbon nanopolyhedra were also bridged by multi-walled carbon nanotubes (MWCNTs, with a diameter of about $12 \mathrm{~nm}$ ). During the high-temperature carbonization process, graphitic carbon structures were formed under the catalyzation of Co metal nanoparticles (Fig. 2i). Besides, the high-magnification TEM image clearly shows interfaces of the embedded nanoparticles with crystal lattice spacings of $0.26 \mathrm{~nm}$ and $0.2 \mathrm{~nm}$, which are in a good agreement with the (111) lattice plane of $\mathrm{CoSe}_{2}$ and Co, respectively (Fig. 2j). 


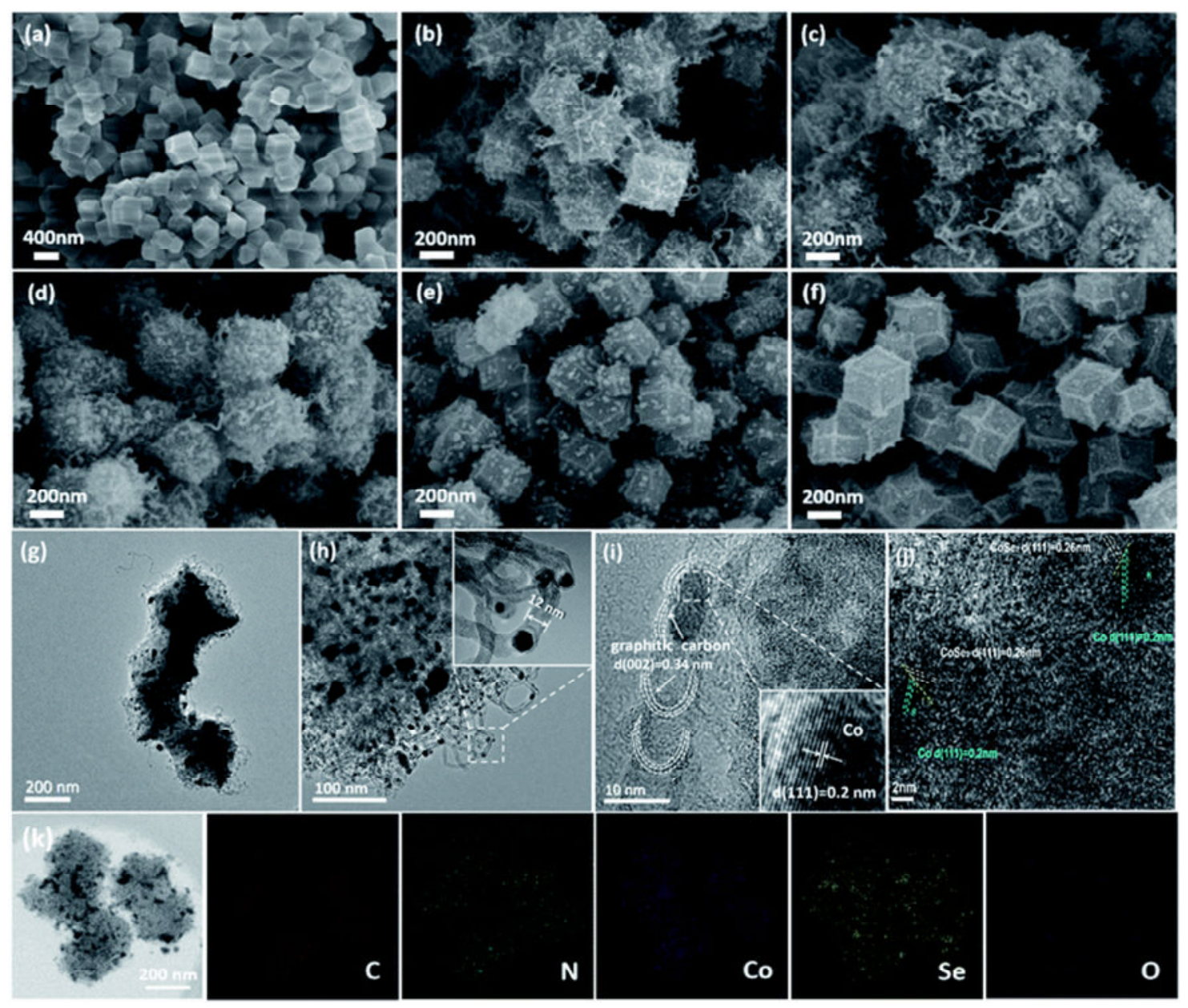

Fig. 2 SEM images of (a) Zn/Co-ZIF-1, (b) Co@NC-CNT-1, (c) $\mathrm{CoSe}_{2} / \mathrm{Co} @ \mathrm{NC}-$ CNT-0.5, (d) $\mathrm{CoSe}_{2} / \mathrm{Co} @ \mathrm{NC}-\mathrm{CNT}-1$, (e) $\mathrm{CoSe}_{2} / \mathrm{Co} @ \mathrm{NC}-\mathrm{CNT}-2$, (f) $\mathrm{CoSe}_{2} / \mathrm{Co} @ \mathrm{NC}-\mathrm{CNT}-5 . \mathrm{TEM}$ images of ( $\mathrm{g}$ and $\mathrm{h}$ ) CoSe $2 / \mathrm{Co} @ \mathrm{NC}-\mathrm{CNT}-1 . \mathrm{HRTEM}$ images of (inside of h) MWCNTs, (i) Co and (j) $\mathrm{CoSe}_{2} / \mathrm{Co}$ nanoparticles. (k) Elemental mapping of $\mathrm{CoSe}_{2} / \mathrm{Co} @ \mathrm{NC}-\mathrm{CNT}-1$. 

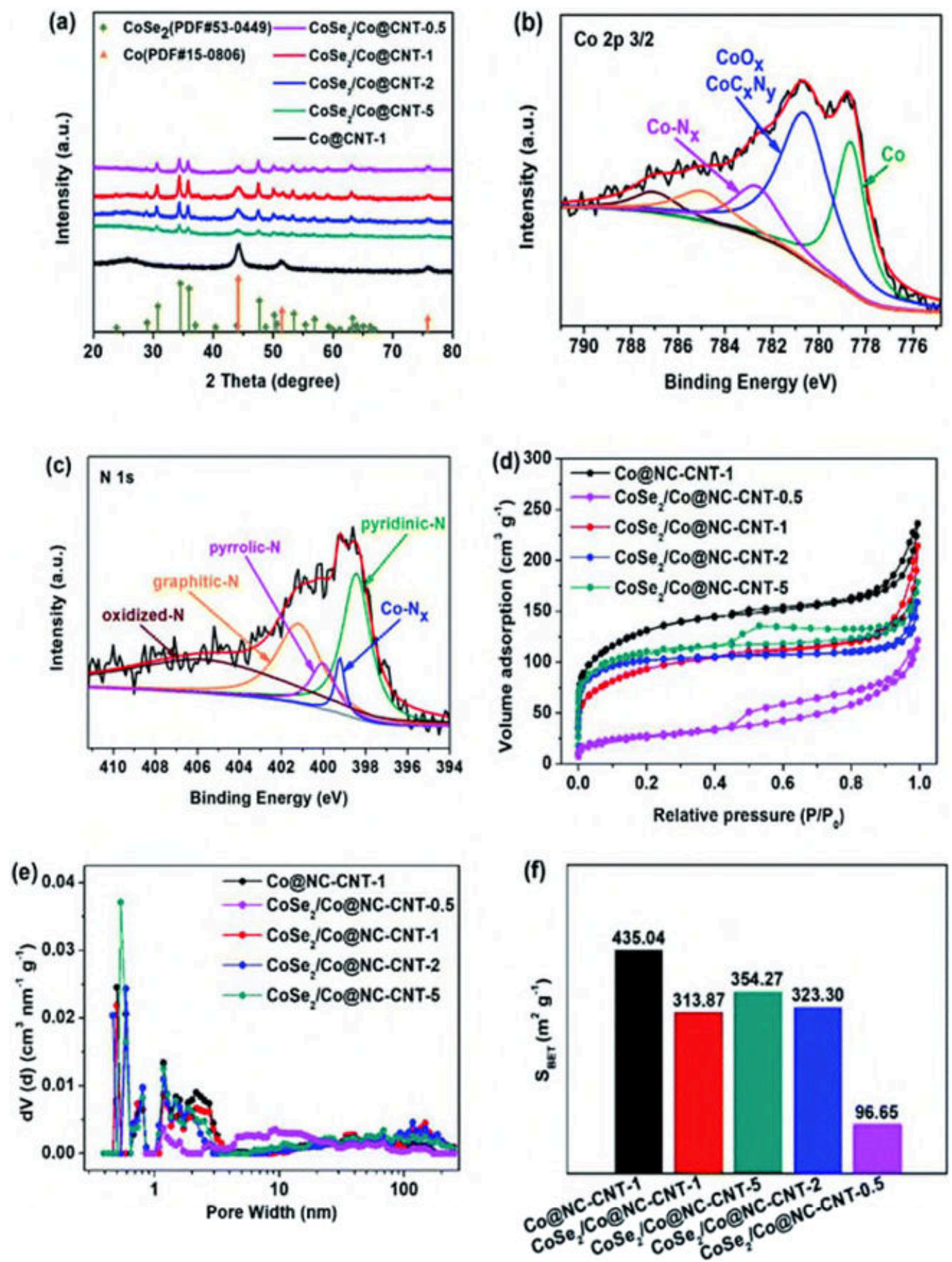

Fig. 3 (a) XRD pattern of Co@NC-CNT-1 and CoSe $2 /$ Co@NC-CNT- $x$ samples. Highresolution XPS spectra of (b) Co 2p 3/2 for CoSe $/$ Co@NC-CNT-1, (c) N 1s for $\mathrm{CoSe}_{2} / \mathrm{Co} @ \mathrm{NC}-\mathrm{CNT}-1$. (d) $\mathrm{N}_{2}$ sorption isotherms for Co@NC-CNT-1 and $\mathrm{CoSe}_{2} / \mathrm{Co} @ \mathrm{NC}-\mathrm{CNT}-x$ samples. (e) Pore-size distributions of Co@NC-CNT-1 and $\mathrm{CoSe}_{2} / \mathrm{Co} @ \mathrm{NC}-\mathrm{CNT}-x$. (f) BET surface areas of Co@NC-CNT-1 and $\mathrm{CoSe}_{2} / \mathrm{Co} @ \mathrm{NC}-\mathrm{CNT}-x$.

Elemental mapping indicated that $\mathrm{CoSe}_{2} / \mathrm{Co} @ \mathrm{NC}-\mathrm{CNT}-1$ was made mainly of $\mathrm{Co}, \mathrm{Se}, \mathrm{N}$, $\mathrm{C}$ and $\mathrm{O}$, among which $\mathrm{Co}, \mathrm{Se}$ and $\mathrm{N}$ were uniformly distributed throughout the carbon matrix 
(Fig. 2k). The other CoSe $2 / \mathrm{Co} @$ NC-CNT- $x$ derived from Co@NC-CNT- $x$ had similar structures with $\mathrm{CoSe}_{2} / \mathrm{Co} @ \mathrm{NC}-\mathrm{CNT}-1$. Raman spectra were recorded to further study the carbon structure changes in the $\mathrm{CoSe}_{2} / \mathrm{Co} @ \mathrm{NC}-\mathrm{CNTs}$. The two main peaks located at about $1350 \mathrm{~cm}^{-1}$ (D band) and $1580 \mathrm{~cm}^{-1}$ (G band) were related to disordered carbon and graphitic carbon, respectively. Here, the relative intensity ratio of the $\mathrm{G}$ band to the $\mathrm{D}$ band $\left(I_{\mathrm{G}} / I_{\mathrm{D}}\right)$ is usually used to evaluate the graphitization degree of carbon materials. ${ }^{40,41}$ As exhibited in Fig. $\mathrm{S} 3$, the values of $I_{\mathrm{G}} / I_{\mathrm{D}}$ increased with the increase in Co contents, indicating the increase in graphited carbon structures.

To look further into the chemical compositions and elemental valence states, X-ray photoelectron spectroscopy (XPS) measurements of $\mathrm{CoSe}_{2} / \mathrm{Co} @ \mathrm{NC}-\mathrm{CNT}-1$ were carried out. As exhibited in Fig. S4a, the survey scan spectrum of $\mathrm{CoSe}_{2} / \mathrm{Co} @ \mathrm{NC}-\mathrm{CNT}-1$ clearly confirmed the presence of $\mathrm{Co}, \mathrm{Se}, \mathrm{N}, \mathrm{C}$ and $\mathrm{O}$ elements. The high-resolution spectrum of $\mathrm{C} 1 \mathrm{~s}$ was fitted and divided into three peaks: graphitic $\mathrm{sp}^{2}$ carbon at $284.6 \mathrm{eV}, \mathrm{C}=\mathrm{N}$ bonds at 285.9 $\mathrm{eV}$ and $\mathrm{C}-\mathrm{N}$ bonds at $287.6 \mathrm{eV}$, respectively (Fig. S4b $\mathrm{b}_{ \pm}$. The fitting results confirmed the graphitic carbon layers were introduced with nitrogen atoms during the carbonization process. The high-resolution spectrum of Co $2 \mathrm{p}_{3 / 2}$ exhibited three important peaks at 778.6, 780.6 and $782.6 \mathrm{eV}$ (Fig. 3b), which were related to the metallic Co, $\operatorname{CoO}_{x} / \mathrm{CoC}_{x} \mathrm{~N}_{y}$ and $\mathrm{Co}-\mathrm{N}_{x}$, respectively. The Co- $\mathrm{N}_{x}$ moieties, which have been demonstrated to be among the best active sites for ORR, play an important role in improving the ORR performance. The high-resolution spectrum of $\mathrm{N}$ 1s was fitted and divided into five peaks at 398.4, 399.2, 400.1, 401.1 and 405.6 $\mathrm{eV}$, which were in agreement with the pyridinic- $\mathrm{N}, \mathrm{Co}-\mathrm{N}_{x}$, pyrrolic- $\mathrm{N}$, graphitic- $\mathrm{N}$ and oxidized-N, respectively (Fig. 3c). All these $\mathrm{N}$ species have been proven to make a great contribution towards the ORR activity except for oxidized-N. Additionally, as illustrated in Fig S4c and 4d, the $\mathrm{O} 1 \mathrm{~s}$ spectrum was deconvoluted into four peaks at 530.5, 531.1, 532.4 and $53.8 \mathrm{eV}$, associated with the $\mathrm{Co}-\mathrm{O}, \mathrm{C}=\mathrm{O}, \mathrm{Se}-\mathrm{O}$ and $\mathrm{H}-\mathrm{O}-\mathrm{H}$ bonds, respectively. The highresolution spectrum of Se 3d was deconvoluted into three main peaks at 54.1, 55.1 and 58.8 $\mathrm{eV}$, corresponding to $\mathrm{Co}-\mathrm{Se}$, Se-Se and $\mathrm{Se}-\mathrm{O}-\mathrm{Se}$, respectively.

The ORR and OER are types of interfacial reactions, for which abundant porous structures and a large surface area are beneficial. So, nitrogen adsorption/desorption measurements were employed to obtain more detailed information about the porous texture of Co@NC-CNT-1 and $\mathrm{CoSe}_{2} / \mathrm{Co} @$ NC-CNT- $x(x=0.5,1,2,5)$. As displayed in Fig. 3d, all the samples exhibited type IV isotherms with a significant rise at the beginning with loading nitrogen and hysteresis loops appearing at a moderate relative pressure $\left(P / P_{0}>0.4\right)$, revealing the coexistence of microporous and mesoporous structures in the body. As conformed by the pore-size 
distributions (Fig. 3e), the microporous structure was centred at $0.6 \mathrm{~nm}$ while the mesoporous structure was centred at $2.5 \mathrm{~nm}$. Fig. 3f gives the BET surface areas of Co@NC-CNT-1 and $\mathrm{CoSe}_{2} / \mathrm{Co} @$ NC-CNT- $x(x=0.5,1,2,5)$ : 435.04, 96.65, 313.87, 323.30 and $354.27 \mathrm{~m}^{2} \mathrm{~g}^{-1}$, respectively. It could be obviously observed that the BET surface area of Co@NC-CNT-1 (435.04 $\mathrm{m}^{2} \mathrm{~g}^{-1}$ ) was larger than that of CoSe $2 /$ Co@NC-CNT-1 (313.87 $\mathrm{m}^{2} \mathrm{~g}^{-1}$ ), while $\mathrm{CoSe}_{2} / \mathrm{Co} @ \mathrm{NC}-\mathrm{CNT}-1$ had the best ORR and OER performance. It was revealed that the electrocatalytic activity is not entirely determined by the specific surface area and active $\mathrm{CoSe}_{2} / \mathrm{Co}$ heterostructures can efficiently improve the electrocatalytic performance in ORR and OER. In addition, CoSe $2 / \mathrm{Co} @ \mathrm{NC}-\mathrm{CNT}-5$ had the largest BET surface area $\left(354.27 \mathrm{~m}^{2} \mathrm{~g}^{-1}\right)$ among the $\mathrm{CoSe}_{2} / \mathrm{Co} @$ NC-CNT- $x$ electrocatalysts, while $\mathrm{CoSe}_{2} / \mathrm{Co} @ \mathrm{NC}-\mathrm{CNT}-0.5$ had the least specific surface area $\left(96.65 \mathrm{~m}^{2} \mathrm{~g}^{-1}\right)$, suggesting that the increase in Co content causes a decrease in the specific surface area. Such high BET surface areas and hierarchically porous structures can provide more active sites and reaction locations to improve the ORR and OER performance of the electrocatalyst.

With the various bits of structural information mentioned above, we studied the electrocatalytic properties of $\mathrm{CoSe}_{2} / \mathrm{Co} @ \mathrm{NC}-\mathrm{CNT}-x(x=0.5,1,2,5)$ in alkaline media $(0.1 \mathrm{M}$ $\mathrm{KOH}$ and $1 \mathrm{M} \mathrm{KOH})$. Cyclic voltammetry $(\mathrm{CV})$ and linear sweep voltammetry (LSV) curves were first recorded by the rotation disk electrode (RDE) and L-type glassy carbon electrode measurements. As a comparison, commercial $20 \mathrm{wt} \%$ of $\mathrm{Pt} / \mathrm{C}$, commercial $\mathrm{IrO}_{2}(\mathrm{Ir} \geq 84.5 \%)$ and the corresponding Co@ NC-CNT-1 electrodes were measured under the same conditions, respectively. As shown in Fig. 4a, b and S6, the CV curves for all the electrocatalysts exhibited a nearly rectangular shape and no reduction peak appeared in the Ar-saturated solution in the ORR. On the contrary, all the electrocatalysts, except for the contrastive $\mathrm{Pt} / \mathrm{C}$, exhibited a well-defined reduction peak from $0.7 \mathrm{~V}$ to $0.9 \mathrm{~V} v s$. $\mathrm{RHE}$ in $\mathrm{O}_{2}$-saturated solution, confirming their obvious electrocatalytic activities for ORR. The ORR performances for all the electrocatalysts were further evaluated using the LSV technique at a rotation speed of 1600 rpm. As displayed in Fig. 4c and Table S1, \pm compared to the other $\mathrm{CoSe}_{2} / \mathrm{Co} @ \mathrm{NC}-\mathrm{CNT}-x(x=$ $0.5,2,5)$, it could be obviously observed that CoSe $2 / \mathrm{Co} @ N C-C N T-1$ possessed the best electrocatalytic performance, which was even comparable to that of $\mathrm{Pt} / \mathrm{C}$. The values for $\mathrm{CoSe}_{2} / \mathrm{Co} @ \mathrm{NC}-\mathrm{CNT}-1$ and Pt/C for the diffusion-limited current density, onset potential and half-wave potential were 6.82 and $6.52 \mathrm{~mA} \mathrm{~cm}^{-2}, 0.95$ and $1.06 \mathrm{~V}$ (vs. RHE), 0.84 and $0.86 \mathrm{~V}$ (vs. RHE), respectively. Those are superior to the other $\mathrm{CoSe}_{2} / \mathrm{Co} @ \mathrm{NC}-\mathrm{CNT}-x$ electrocatalysts $(x=0.5,2,5)$, especially for Co@NC-CNT-1 (diffusion-limited current density of $5.47 \mathrm{~mA}$ $\mathrm{cm}^{-2}$, onset potential of $0.9 \mathrm{~V} v s$. RHE, and half-wave potential of $0.82 \mathrm{~V} v s$. RHE), confirming 
the superiority of the active $\mathrm{CoSe}_{2} / \mathrm{Co}$-embedded porous carbon structure. Furthermore, the Tafel slopes of $\mathrm{CoSe}_{2} / \mathrm{Co} @ \mathrm{NC}-\mathrm{CNT}-x(x=0.5,1,2,5)$ were all smaller than for $\mathrm{Pt} / \mathrm{C}$ in Fig. $\underline{4 \mathrm{~d}}$, but the Tafel slope of $\mathrm{CoSe}_{2} / \mathrm{Co} @ \mathrm{NC}-\mathrm{CNT}-1$ was the smallest among these samples, and it also had the best ORR performance. Therefore, it is clear that a smaller Tafel slope could confirm a better ORR performance in electrocatalysts. 

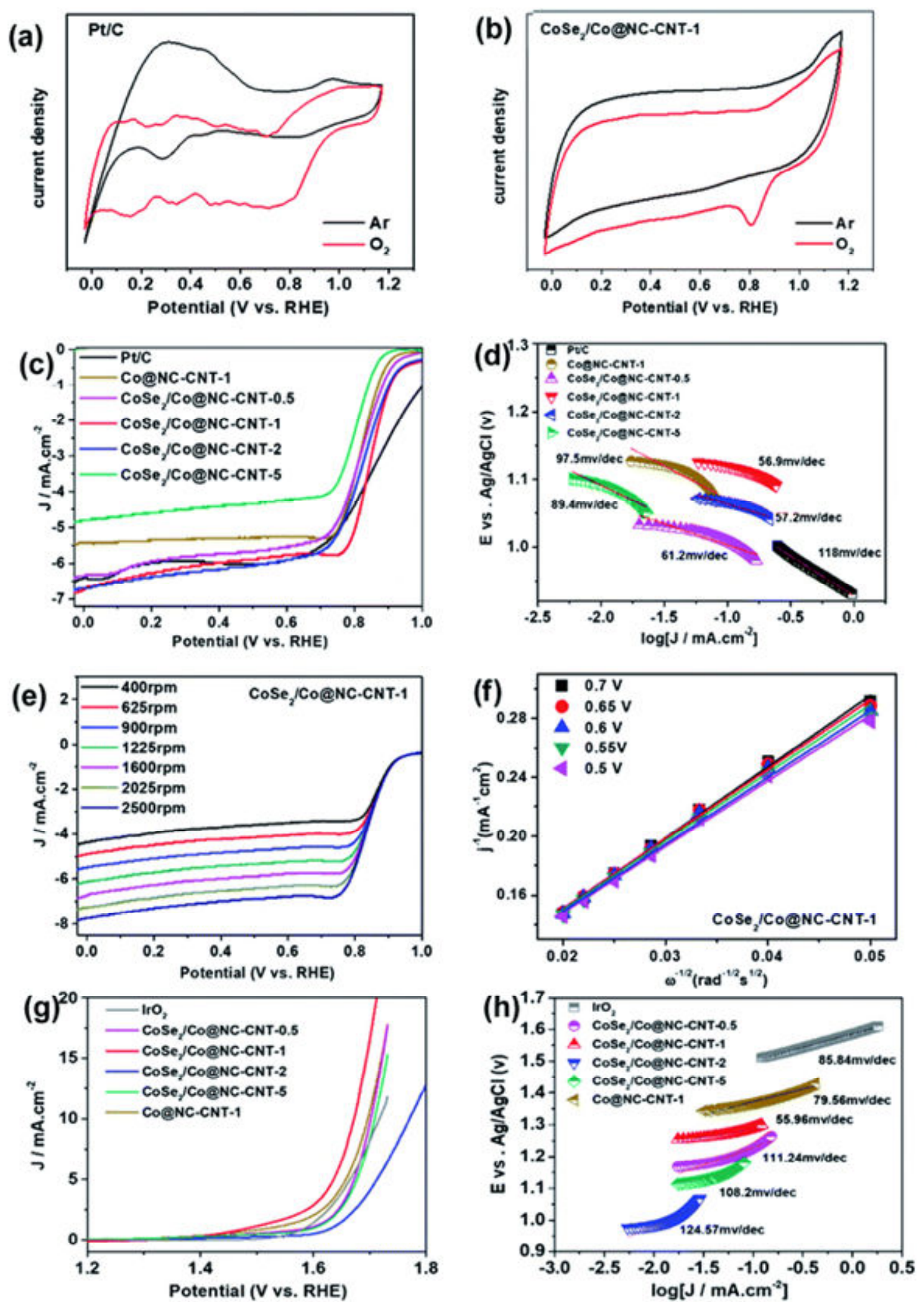
Fig. 4 CV curves of (a) commercial Pt/C and (b) CoSe $2 /$ Co@NC-CNT-1 in Ar-saturated and $\mathrm{O}_{2}$-saturated 0.1 M KOH. (c) LSV curves of different samples for ORR in $\mathrm{O}_{2}$-saturated $0.1 \mathrm{M}$ $\mathrm{KOH}$ at a rotation rate of $1600 \mathrm{rpm}$. (d) Tafel plots of different samples for ORR. (e) LSV curves of $\mathrm{CoSe}_{2} / \mathrm{Co} @ N C-C N T-1$ for ORR at different rotation speeds. (f) Koutecky-Levich plots of $\mathrm{CoSe}_{2} / \mathrm{Co} @ N C-C N T-1$ at different potentials. (g) LSV curves of different samples for OER in $\mathrm{O}_{2}$-saturated $1 \mathrm{M} \mathrm{KOH}$. (h) Tafel plots of different samples for OER.

To gain more insights into the ORR activity and the reaction kinetics, the ORR polarization curves of the $\mathrm{CoSe}_{2} / \mathrm{Co} @ \mathrm{NC}-\mathrm{CNT}-x$ and Pt/C electrocatalysts were measured at different rotation speeds from 400 to $2500 \mathrm{rpm}$ in $\mathrm{O}_{2}$-saturated $0.1 \mathrm{M} \mathrm{KOH}$. As shown in Fig. 4e and $\mathrm{S} 7$, t the diffusion-limited current density increased with the rotation speed increasing due to the shorter diffusion paths at high speed. The electron-transfer number $(n)$ in the reaction path was calculated based on the Koutecky-Levich (K-L) equation. As displayed in Fig. $4 \mathrm{f}$ and $\mathrm{S} 8, \pm$ the $\mathrm{K}-\mathrm{L}$ plots at various potentials displayed great linearity and close slope values, which indicated that these electrocatalysts have similar electron-transfer numbers for the ORR. The electron-transfer number of $\mathrm{CoSe}_{2} / \mathrm{Co} @ \mathrm{NC}-\mathrm{CNT}-1$ was calculated to be 3.8-4.0 at a potential range from $0.5-0.7 \mathrm{~V}$ (vs. RHE), suggesting the ORR activity was catalyzed by $\mathrm{CoSe}_{2} / \mathrm{Co} @ \mathrm{NC}-\mathrm{CNT}-1$ mainly through a four-electron transfer process. In Fig. 4g, $\mathrm{CoSe}_{2} / \mathrm{Co} @ \mathrm{NC}-\mathrm{CNT}-x(x=0.5,1,2,5)$ displayed better OER electrocatalytic performance than $\mathrm{IrO}_{2}$, and $\mathrm{CoSe}_{2} / \mathrm{Co} @ \mathrm{NC}-\mathrm{CNT}-1$ possessed outstanding electrocatalytic property, with a potential of $1.69 \mathrm{~V} v s$. RHE at $10 \mathrm{~mA} \mathrm{~cm}^{-2}$. Additionally, the Tafel slope of $\mathrm{CoSe}_{2} / \mathrm{Co} @ \mathrm{NC}$ CNT- $x(x=0.5,1,2,5)$ and $\mathrm{IrO}_{2}$ are displayed in Fig. 4h, and it could be seen that the Tafel slope of $\mathrm{CoSe}_{2} / \mathrm{Co} @ \mathrm{NC}-\mathrm{CNT}-1$ was the smallest among these samples. In the meantime, CoSe $/$ Co@NC-CNT-1 also had the best OER performance among these samples and $\mathrm{IrO}_{2}$, confirming the Tafel slope was lower and the OER performance was better.

To evaluate the electrochemical active surface area (ECSA), the double layer capacitance $\left(C_{\mathrm{dl}}\right)$ was measured to assess the value of ECSA. Finally the ECSA value of $\mathrm{CoSe}_{2} / \mathrm{Co} @ \mathrm{CNT}$ 1 was roughly calculated to $1472.19 \mathrm{~cm}^{2}$, which was the largest ECSA value among these five samples and implied it had the most electrocatalytic active sites for ORR.

In addition to the electrocatalytic activity, the long-term stability and methanol tolerance ability are also important factors to evaluate the electrocatalytic performance of OER and ORR electrocatalysts. To evaluate the long-time stability, all the electrocatalysts were cycled in a voltage range from $-0.4 \mathrm{~V}$ to $0 \mathrm{~V}(v s . \mathrm{Ag} / \mathrm{AgCl})$ at a scan speed of $50 \mathrm{mV} \mathrm{s}^{-1}$ in $\mathrm{O}_{2}$-saturated 0.1 M KOH for ORR, in which they can both be involved in reduction reaction processes. After a continuous $10000 \mathrm{CV}$ cycles, the LSV curves of all the electrocatalyst were tested again. As 
shown in Fig. 5a, b and S9a-f, almost unchanged with only a little negative movement of $11 \mathrm{mV}$, while the $\mathrm{Pt} / \mathrm{C}$ electrocatalyst suffered from a larger negative movement of about $42 \mathrm{mV}$, indicating the superb stability compared to $\mathrm{Pt} / \mathrm{C}$ and the other electrocatalysts. Furthermore, the methanol resistance of $\mathrm{CoSe}_{2} / \mathrm{Co} @ \mathrm{NC}-\mathrm{CNT}-1$ was also measured by adding $3 \mathrm{M}$ methanol at $300 \mathrm{~s}$, and it was observed that there was almost no variation in the LSV curves of $\mathrm{CoSe}_{2} / \mathrm{Co} @ \mathrm{NC}-\mathrm{CNT}-1$, while the $\mathrm{Pt} / \mathrm{C}$ electrocatalyst appeared to show a continuous decrease in activity due to the methanol poisoning reaction (Fig. 5c and d). In addition, the OER LSV curves of all the electrocatalysts were tested, with the results shown in Fig. 5e, f and S9h-1, \pm where after a continuous 10000 $\mathrm{CV}$ cycles, the potential gap of $\mathrm{CoSe}_{2} / \mathrm{Co} @ \mathrm{NC}-\mathrm{CNT}-1$ was narrower than $\mathrm{IrO}_{2}$, which indicated $\mathrm{CoSe}_{2} / \mathrm{Co} @ \mathrm{NC}-\mathrm{CNT}-1$ was more stable than Pt/C in alkaline solution. The results here demonstrate that $\mathrm{CoSe}_{2} / \mathrm{Co} @ \mathrm{NC}-\mathrm{CNT}-1$ has a strong resistance against cross-over effects, making it a promising electrocatalyst for direct methanol fuel cells. 

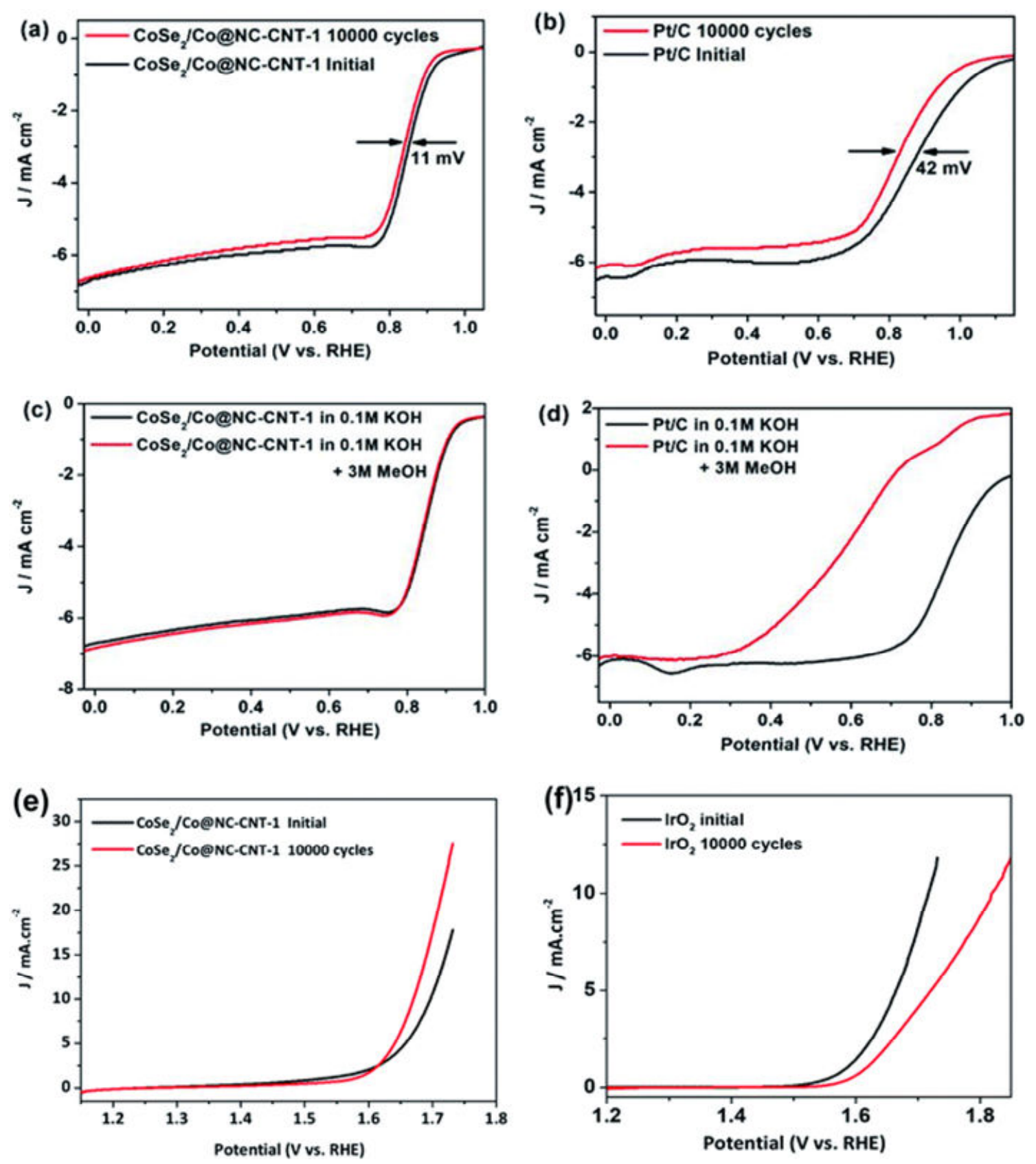

Fig. 5 LSV curves of (a) CoSe 2 /Co@NC-CNT-1 and (b) commercial Pt/C for ORR before and after 10000 potential cycles in $\mathrm{O}_{2}$-saturated $0.1 \mathrm{M} \mathrm{KOH}$. LSV curves of (c) $\mathrm{CoSe}_{2} / \mathrm{Co} @ N C$ CNT-1 and (d) commercial Pt/C in $\mathrm{O}_{2}$-saturated $0.1 \mathrm{M} \mathrm{KOH}$ without and with $3 \mathrm{M} \mathrm{MeOH}$. LSV curves of (e) CoSe 2 /Co@NC-CNT-1 and (f) commercial IrO ${ }_{2}$ for OER before and after 10 000 potential cycles in $\mathrm{O}_{2}$-saturated $1 \mathrm{M} \mathrm{KOH}$.

To explore the practical application of $\mathrm{CoSe}_{2} / \mathrm{Co} @ \mathrm{NC}-\mathrm{CNT}-1$, a conventional liquid Znair battery (Fig. 6a) was assembled by using carbon paper coated with $\mathrm{CoSe}_{2} / \mathrm{Co} @ \mathrm{NC}-\mathrm{CNT}-1$ as the air cathode and polished $\mathrm{Zn}$ sheet as the anode, respectively, with an aqueous solution of $6 \mathrm{M} \mathrm{KOH}$ and $0.2 \mathrm{M} \mathrm{Zn(Ac)} 2$ utilized as the electrolyte. For comparison, the commercial 20 $\mathrm{wt} \% \mathrm{Pt} / \mathrm{C}+\mathrm{IrO}_{2}$ electrocatalyst was also prepared as a $\mathrm{Zn}$-air battery for further tests. As 
shown in Fig. 6b, the open circuit voltage of the rechargeable $\mathrm{Zn}$-air battery with $\mathrm{CoSe}_{2} / \mathrm{Co} @ \mathrm{NC}-\mathrm{CNT}-1$ was measured to be $1.405 \mathrm{~V}$, which was close to that of the Pt/C +

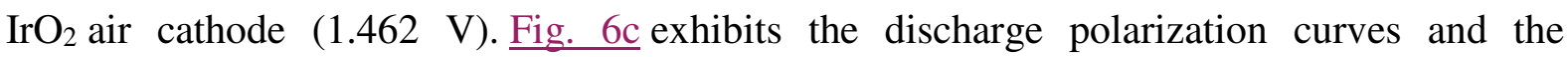
corresponding power density plots of a single battery, where the maximum power density of

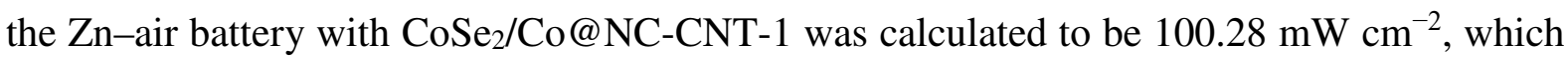
was higher than that of the $\mathrm{Pt} / \mathrm{C}+\mathrm{IrO}_{2}$ electrocatalyst $\left(75.9132 \mathrm{~mW} \mathrm{~cm}{ }^{-2}\right)$. The excellent electrocatalytic performance of $\mathrm{CoSe}_{2} / \mathrm{Co} @ \mathrm{NC}-\mathrm{CNT}-1$ is due to the appropriate number of $\mathrm{CoSe}_{2} / \mathrm{Co}$ nanoheteroparticles and the porous carbon matrix, which enhance the diffusion of $\mathrm{O}_{2}$ and the association among the active sites.
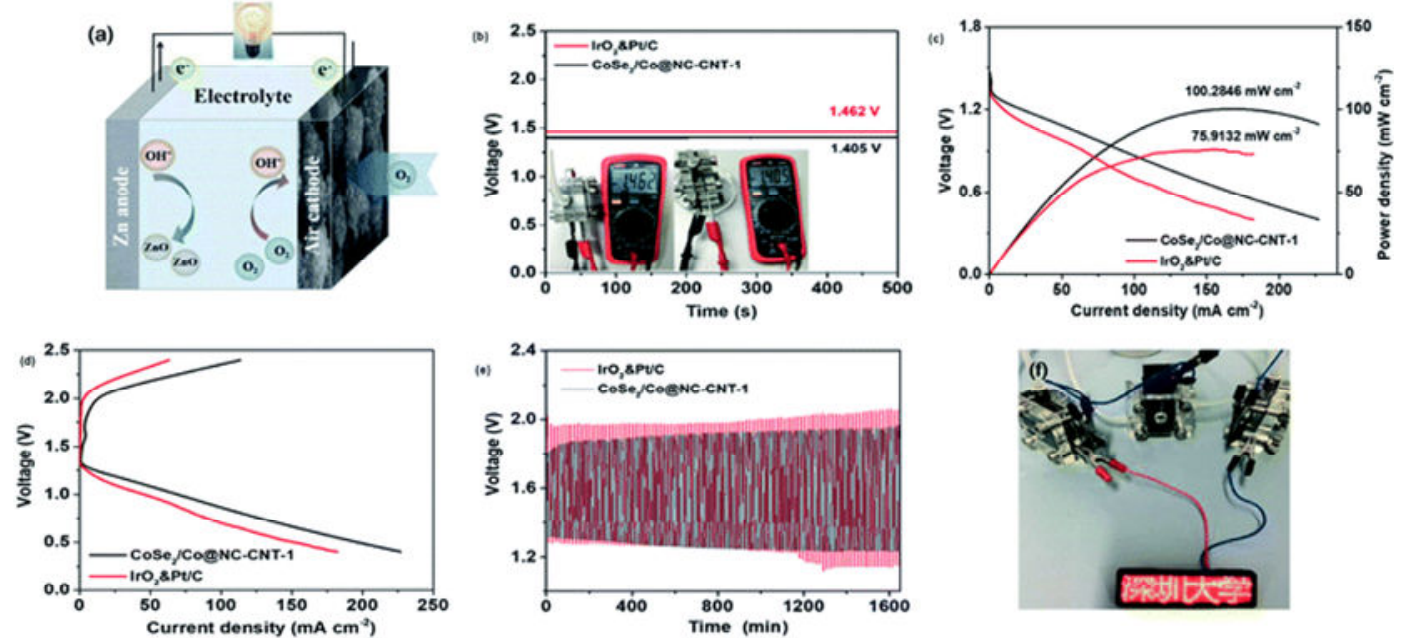

Fig. 6 (a) Schematic illustration of the liquid Zn-air battery. (b) Open circuit plots of the $\mathrm{Zn}$-air battery with $\mathrm{CoSe}_{2} / \mathrm{Co} @ \mathrm{NC}-\mathrm{CNT}-1$ and $\mathrm{IrO}_{2} \& \mathrm{Pt} / \mathrm{C}$ served as the air cathode, respectively, inset: the corresponding digital photo of the $\mathrm{Zn}$-air battery based on $\mathrm{CoSe}_{2} / \mathrm{Co} @ \mathrm{NC}-\mathrm{CNT}-1$ catalyst with an open circuit voltage of 1.405 V. (c) Discharge polarization curves and corresponding power density curves of the $\mathrm{Zn}$-air batteries equipped with $\mathrm{CoSe}_{2} / \mathrm{Co} @ \mathrm{NC}-\mathrm{CNT}-1$ and $\mathrm{IrO}_{2} \& \mathrm{Pt} / \mathrm{C}$ air cathodes. (d) Charge and discharge polarization curves of Zn-air batteries with CoSe $2 / \mathrm{Co} @ \mathrm{NC}-\mathrm{CNT}-1$ and Pt/C air cathode, respectively. (e) Long-term cycling stability at $10 \mathrm{~mA} \mathrm{~cm}{ }^{-2}$ with $10 \mathrm{~min}$ per cycle. (f) Digital photo of a glowing red LED panel powered by three $\mathrm{Zn}$-air batteries.

For a rechargeable $\mathrm{Zn}$-air battery, a small difference value between the charge and discharge voltage are also critical. ${ }^{5,6}$ Fig. $6 \mathrm{~d}$ displays the charge and discharge polarization curves, as expected, where the charge-discharge voltage gap of the $\mathrm{Zn}$-air battery with the $\mathrm{CoSe}_{2} / \mathrm{Co} @ \mathrm{NC}-\mathrm{CNT}-1$ cathode $(696 \mathrm{mV})$ was lower than that of the $\mathrm{Pt} / \mathrm{C}+\mathrm{IrO}_{2}$ cathode $(905$ $\mathrm{mV}$ ) at a current density of $10 \mathrm{~mA} \mathrm{~cm}{ }^{-2}$, which implied that the CoSe $/$ Co@NC-CNT-1 cathode could improve the recharge ability of the Zn-air battery. Furthermore, the cyclic 
stability of $\mathrm{CoSe}_{2} / \mathrm{Co} @ \mathrm{NC}-\mathrm{CNT}-1$ for the Zn-air battery was also measured by galvanostatic charge and discharge tests at a current density of $10 \mathrm{~mA} \mathrm{~cm}^{-2}$ (with $5 \mathrm{~min}$ for charging, $5 \mathrm{~min}$ for discharging and $1 \mathrm{~min}$ break after each assignment). As demonstrated in Fig. 6e, during 1700 min (140 cycles), the charge-discharge voltage gap of the CoSe $2 / \mathrm{Co} @$ NC-CNT-1-based air cathode was always smaller than that of the $\mathrm{Pt} / \mathrm{C}+\mathrm{IrO}_{2}$-based air cathode in the $\mathrm{Zn}$-air battery. Additionally, the CoSe $/$ Co@NC-CNT-1-based Zn-air battery exhibited a better cycling stability than the $\mathrm{Pt} / \mathrm{C}+\mathrm{IrO}_{2}$-based $\mathrm{Zn}$-air battery. The remarkable duration of $\mathrm{CoSe}_{2} / \mathrm{Co} @ \mathrm{NC}-\mathrm{CNT}-1$ in the oxygen reaction benefited from its stable porous structure and appropriate number of $\mathrm{CoSe}_{2} / \mathrm{Co}$ nanoheteroparticles. Furthermore, a red LED panel with the Chinese words "Shenzhen University" could be lit up by three $\mathrm{Zn}$-air batteries connected in series (Fig. 6f), demonstrating the materials promise in practical applications in $\mathrm{Zn}$-air batteries.

\section{Experimental}

\section{Reagents}

Zinc nitrate hexahydrate $\left[\mathrm{Zn}\left(\mathrm{NO}_{3}\right)_{2} \cdot 6 \mathrm{H}_{2} \mathrm{O}, 99.99 \%\right]$, cobalt nitrate hexahydrate $\left[\mathrm{Co}\left(\mathrm{NO}_{3}\right)_{2} \cdot 6 \mathrm{H}_{2} \mathrm{O}, 99.99 \%\right]$, Se powder $(99.9 \%)$ and methanol (MeOH, 99.5\%) were purchased from Aladdin Industrial Corporation $(\mathrm{CHN})$. A commercial $20 \mathrm{wt} \% \mathrm{Pt} / \mathrm{C}$ catalyst was purchased from Alfa Aesar (USA). A commercial $\mathrm{IrO}_{2}$ ( $\mathrm{Ir}>84 \%$ ) catalyst was purchased from Aladdin Industrial Corporation (CHN). Nafion solution (5 wt\%) and 2-methylimidazole $(98.0 \%)$ were acquired from Sigma-Aldrich (USA). All these reagents were used without any further purification.

\section{Synthesis of hybrid Zn/Co-ZIFs}

The synthesis of hybrid Zn/Co-ZIFs was based on a modified procedure reported in the previous literature. ${ }^{29}$ Typically, solution A was first prepared by dissolving $\mathrm{Zn}\left(\mathrm{NO}_{3}\right)_{2} \cdot 6 \mathrm{H}_{2} \mathrm{O}$ and $\mathrm{Co}\left(\mathrm{NO}_{3}\right)_{2} \cdot 6 \mathrm{H}_{2} \mathrm{O}$ with the desired molar ratio of $\mathrm{Zn}^{2+} / \mathrm{Co}^{2+}(0.5,1,2,5$, equal to $1: 2,1$ : $1,2: 1,5: 1$, respectively) in $200 \mathrm{~mL}$ methanol, with the total molar amount of $\mathrm{Zn}^{2+}$ and $\mathrm{Co}^{2+}$ fixed at $30 \mathrm{mmol}$. solution B was made of 2-methylimidazole $(9.84 \mathrm{~g})$ with $200 \mathrm{~mL}$ methanol and was added to solution A with moderate stirring for $24 \mathrm{~h}$ at room temperature. Then the resulting precipitate was separated by centrifugation and washed thoroughly with methanol twice, and finally dried at $70{ }^{\circ} \mathrm{C}$ for $12 \mathrm{~h}$. The resulting purple product was named as $\mathrm{Zn} / \mathrm{Co}-\mathrm{ZIF}-x$, where $x$ represents the molar ratio of $\mathrm{Zn}^{2+} / \mathrm{Co}^{2+}$.

\section{Synthesis of Co@NC-CNTs}

First, $800 \mathrm{mg}$ of hybrid $\mathrm{Zn} / \mathrm{Co}$-ZIFs were heated to $800{ }^{\circ} \mathrm{C}$ with a heating rate of $2{ }^{\circ} \mathrm{C} \mathrm{min}^{-1}$ and held at $800{ }^{\circ} \mathrm{C}$ for $3 \mathrm{~h}$ under a mixed $\mathrm{H}_{2} / \mathrm{Ar}$ flow $\left(5 \mathrm{vol} \% \mathrm{H}_{2}\right)$ of $100 \mathrm{~mL} \mathrm{~min}^{-1}$, in a vacuum 
tube furnace. Then the Co@NC-CNT- $x$ were obtained after cooling down to room temperature naturally, where $x$ means the sample is derived from hybrid ZIFs with a $\mathrm{Zn}^{2+} / \mathrm{Co}^{2+}$ molar ratio of $x$.

\section{Synthesis of CoSe2/Co@NC-CNTs}

Here, 100 mg of Co@NC-CNT- $x$ obtained above and 500 mg of Se powder were separately added into both ends of a quartz boat. Then this quartz boat was put into a vacuum tube furnace with the Se powder and placed at the upstream side of the carrier $\mathrm{N}_{2}$ flow $\left(100 \mathrm{~mL} \mathrm{~min}^{-1}\right)$, and annealed at $500{ }^{\circ} \mathrm{C}$ for $3 \mathrm{~h}$ with a heating rate of $5{ }^{\circ} \mathrm{C} \mathrm{min}{ }^{-1}$. The resulting product was collected and denoted as $\mathrm{CoSe}_{2} / \mathrm{Co} @ \mathrm{NC}-\mathrm{CNT}-x$, where $x=0.5,1,2,5$, respectively, which indicates that the sample was prepared from the selenization of Co@NC-CNT- $x$.

\section{Materials characterization}

X-ray diffraction (XRD) patterns were recorded on a SmartLab instrument using $\mathrm{Cu} \mathrm{K} \alpha$ radiation $(20 \mathrm{kV}, 200 \mathrm{~mA}, \lambda=1.54178 \AA$ ). Scanning electron microscopy (SEM) images were obtained by using an Hitachi SU-70 field emission scanning electron microscopy system with a voltage of $5 \mathrm{kV}$. Transmission electron microscopy (TEM) and high-resolution transmission electron microscopy (HRTEM) images were acquired on a Joel JEM-2100F instrument at an acceleration voltage of $200 \mathrm{kV} . \mathrm{N}_{2}$ sorption isotherms were investigated on a Micromeritics ASAP 2020 instrument, and the Brunauer-Emmett-Teller (BET) surface areas were calculated from the $\mathrm{N}_{2}$ isotherm curves ranging from a relative pressure of 0 to 0.3 , and the pore-size distributions (PSDs) were calculated using a density functional theory (DFT) method. The valence states of the samples were measured by using a MicroLab 350 X-ray photoelectron spectrometer (XPS).

\section{Electrode preparation and electrochemical tests}

All the electrocatalytic measurements were performed on an electrochemical workstation (VMP-300, Bio-Logic Science Instruments) using a three-electrode system in 0.1 M aqueous $\mathrm{KOH}$ electrolyte solution for ORR and $1 \mathrm{M}$ aqueous $\mathrm{KOH}$ electrolyte solution for OER. $\mathrm{A} \mathrm{Pt}$ wire and an $\mathrm{Ag} / \mathrm{AgCl}$ (filled with $3.5 \mathrm{M} \mathrm{KCl}$ solution) electrodes were used as the counter and reference electrodes, respectively. A surface-coated glassy carbon (CG) rotating disk electrode (RDE) was employed as the ORR working electrode (disc area of $0.19625 \mathrm{~cm}^{2}$ ) and an L-type glassy carbon electrode was used as the OER working electrode (disc area of $0.19625 \mathrm{~cm}^{2}$ ). The catalyst ink was made by weighing $1 \mathrm{mg}$ of as-prepared samples to disperse in a mixed solution that included $4 \mu \mathrm{L}$ of Nafion solution ( $5 \mathrm{wt} \%$ ) and $196 \mu \mathrm{L}$ of ethanol, and then the mixture was ultrasonicated for about $30 \mathrm{~min}$ to get an homogenous solution. After that, $10 \mu \mathrm{L}$ of the catalyst ink was cast onto the surface of the working electrode, followed by drying at 
room temperature for $30 \mathrm{~min}$. A commercial $20 \mathrm{wt} \% \mathrm{Pt} / \mathrm{C}$-loaded $\mathrm{RDE}$ and a commercial $\mathrm{IrO}_{2}$ loaded L-type glassy carbon electrode were prepared by the same procedure. Specially, before the electrochemical tests, the electrolyte was saturated by a pure $\mathrm{O}_{2}$ or Ar gas flow for at least $30 \mathrm{~min}$.

For ORR, the cyclic voltammetry $(\mathrm{CV})$ experiments were performed in saturated Ar and $\mathrm{O}_{2}$ in $0.1 \mathrm{M} \mathrm{KOH}$ by applying a voltage range from $-1 \mathrm{~V}$ to $0.2 \mathrm{~V}(v s . \mathrm{Ag} / \mathrm{AgCl})$ with a scan rate of $50 \mathrm{mV} \mathrm{s}^{-1}$, and the linear sweep voltammetry (LSV) measurements were conducted in $\mathrm{O}_{2}$-saturated $0.1 \mathrm{M} \mathrm{KOH}$ by applying a voltage range from $-1 \mathrm{~V}$ to $0.2 \mathrm{~V}$ (vs. $\mathrm{Ag} / \mathrm{AgCl}$ ) with a scan rate of $10 \mathrm{mV} \mathrm{s}^{-1}$ and varied rotating speed (400-2500 rpm). In the OER, the cyclic voltammetry (CV) experiments and the linear sweep voltammetry (LSV) measurements were performed in saturated $\mathrm{O}_{2} 1 \mathrm{M} \mathrm{KOH}$, applying a voltage range from $-1 \mathrm{~V}$ to $0.2 \mathrm{~V}$ (vs. $\mathrm{Ag} / \mathrm{AgCl}$ ) with a scan rate of $5 \mathrm{mV} \mathrm{s}^{-1}$. All the electrochemical measurements were carried out at room temperature.

All the potentials were measured $v s . \mathrm{Ag} / \mathrm{AgCl}(3.5 \mathrm{M} \mathrm{KCl})$ reference electrode referring to the reversible hydrogen electrode (RHE) scale according to the Nernst equation:

$$
E_{\mathrm{RHE}}=E_{\mathrm{Ag} / \mathrm{AgCl}}+E_{0}+0.059 \mathrm{pH}
$$

where $E_{\mathrm{RHE}}$ is the converted potential vs. RHE, $E_{\mathrm{Ag} / \mathrm{AgCl}}$ is the experimental potential measured vs. $\mathrm{Ag} / \mathrm{AgCl}$ and $E_{0}$ is the standard potential of $\mathrm{Ag} / \mathrm{AgCl}$ at $25^{\circ} \mathrm{C}(0.205 \mathrm{~V})$.

Moreover, the cyclic voltammetry was carried out to assess the electrochemical doublelayer capacitance $\left(C_{\mathrm{dl}}\right)$ at $50 \mathrm{mV} \mathrm{s}^{-1}$.

$$
C_{\mathrm{dl}}=\frac{1}{2 s v\left(V_{\mathrm{a}}-V_{\mathrm{b}}\right)} \int_{V_{\mathrm{b}}}^{V_{\mathrm{a}}} I(V) \mathrm{d} V
$$

where $s$ is defined as the area of activity for the materials in the glassy carbon electrode $\left(\mathrm{cm}^{2}\right), V_{\mathrm{a}}$ is defined as the final electropotential $(\mathrm{V})$ and $V_{\mathrm{b}}$ is the initial electropotential $(\mathrm{V}), v$ is the scan rate $\left(\mathrm{V} \mathrm{s}^{-1}\right)$ and $I(V)$ is the measuring current $(\mathrm{A})$.

Also, a specific capacitance $\left(20-60 \mu \mathrm{F} \mathrm{cm} \mathrm{cm}^{-2}\right)$ of $40 \mu \mathrm{F} \mathrm{cm}$ was applied to calculate the electrochemical active surface area (ECSA). 
$\mathrm{ECSA}=\frac{C_{\mathrm{dl}}}{40 \mu \mathrm{F} \mathrm{cm}^{-2}} \mathrm{~cm}_{\mathrm{ECSA}}^{2}$

The corresponding number of electrons transferred $(n)$ could be calculated by the following Koutecky-Levich (K-L) equations:

$\frac{1}{j}=\frac{1}{j_{\mathrm{K}}}+\frac{1}{j_{\mathrm{L}}}=\frac{1}{j_{\mathrm{K}}}+\frac{1}{B \omega^{1 / 2}}$

$B=0.2 n F C_{0}\left(D_{0}\right)^{2 / 3} v^{-1 / 6}$

$j_{\mathrm{K}}=n F k C_{0}$

where $j$ represents the measured current density, $j_{\mathrm{L}}$ and $j_{\mathrm{K}}$ represent the diffusion-limiting current density and kinetic current density, respectively, and $\omega$ is the disk angular speed $(v=$ $2 \pi N, N$ is the linear rotating speed). Also, $F$ is the Faraday constant equal to $96485 \mathrm{C}$ $\mathrm{mol}^{-1}$ and $n$ represents the overall number of transferred electrons. Other parameters are defined as follows: $C_{0}$ is the molar concentration of $\mathrm{O}_{2}\left(1.2 \times 10^{-6} \mathrm{~mol} \mathrm{~cm}^{-3}\right) ; D_{0}$ is the diffusion coefficient of $\mathrm{O}_{2}$ in $0.1 \mathrm{M} \mathrm{KOH}\left(1.9 \times 10^{-5} \mathrm{~cm}^{2} \mathrm{~s}^{-1}\right)$; $v$ is the kinematic viscosity for the electrolyte $\left(0.01 \mathrm{~cm}^{2} \mathrm{~s}^{-1}\right)$, and $k$ is the electron-transfer rate constant.

\section{Conclusions}

In conclusion, we successfully designed and prepared $\mathrm{CoSe}_{2} / \mathrm{Co}$ nanoparticles embedded in hierarchically porous Co, $\mathrm{N}$ co-doped carbon nanopolyhedra/nanotubes through a two-step high-temperature process. The optimized $\mathrm{CoSe}_{2} / \mathrm{Co} @ \mathrm{NC}-\mathrm{CNT}-1$ was exploited as an ORR and OER electrocatalyst in alkaline medium, and exhibited superior electrocatalytic performance through a nearly four-electron process. In the ORR, the values of the diffusion-limited current density, onset potential and half-wave potential for $\mathrm{CoSe}_{2} / \mathrm{Co} @ \mathrm{NC}-\mathrm{CNT}-1$ were $6.82 \mathrm{~mA}$ $\mathrm{cm}^{-2}, 0.95 \mathrm{~V}$ (vs. RHE), and $0.84 \mathrm{~V}$ (vs. RHE) respectively, while it also had a potential of 1.69 $\mathrm{V}$ vs. RHE for the OER at $10 \mathrm{~mA} \mathrm{~cm}{ }^{-2}$. $\mathrm{CoSe}_{2} / \mathrm{Co} @ \mathrm{NC}-\mathrm{CNT}-1$ also possessed extraordinary long-term stability and a methanol tolerance ability in comparison to a commercial $\mathrm{Pt} / \mathrm{C}$ catalyst or commercial $\mathrm{IrO}_{2}$ catalyst. The outstanding ORR and OER performances of $\mathrm{CoSe}_{2} / \mathrm{Co} @ \mathrm{NC}-\mathrm{CNT}-1$ should be ascribed to the close combination of $\mathrm{CoSe}_{2} / \mathrm{Co}$ nanoheteroparticles with the doped carbon matrix, which possessed a high surface area, a highly graphitized and porous carbon structure, conductive CNTs and uniform Co and N 
doping. Those characteristics are beneficial to the transfer of electrons and the transport of the electrolyte. Herein, those superior structures and an appropriate number of $\mathrm{CoSe}_{2} / \mathrm{Co}$ nanoheteroparticles enabled $\mathrm{CoSe}_{2} / \mathrm{Co} @ \mathrm{NC}-\mathrm{CNT}-1$ to show the best catalytic performance among the series $\mathrm{CoSe}_{2} / \mathrm{Co} @ \mathrm{NC}-\mathrm{CNT}-x(x=0.5,1,2,5)$. In addition, a fabricated Zn-air battery equipped with the $\mathrm{CoSe}_{2} / \mathrm{Co} @ \mathrm{NC}-\mathrm{CNT}-1$ cathode also exhibited a higher peak power density and discharge stability than Pt/C. Considering the activity of $\mathrm{CoSe}_{2} / \mathrm{Co} @ \mathrm{NC}-\mathrm{CNTs}$ in this study, this material also has promise for use in advanced electrodes in other areas of energy storage and conversion, such as water splitting and lithium-ion batteries.

\section{Conflicts of interest}

There are no conflicts to declare.

\section{Acknowledgements}

We thank the editor and reviewers for their valuable comments and suggestions and Shenzhen University for the financial support. This research work was supported by National Natural Science Foundation of China (No. 51202150 and 51272161), Science and Technology R\&D Program of Shenzhen (JCYJ20150324141711663, JCYJ20160422112012739 and JCYJ20170818100134570), the Program of Introducing Innovative Research Team in Dongguan (No.2014607109), and the Foundation of the State Key Laboratory of Solidification Processing in NWPU (SKLSP201110).

\section{references}

1. D. Guo, S. Han, R. Ma, Y. Zhou, Q. Liu, J. Wang and Y. Zhu, Microporous Mesoporous Mater., 2018, 270, 1-9 .

2. B. Volosskiy, H. Fei, Z. Zhao, S. Lee, M. Li, Z. Lin, B. Papandrea, C. Wang, Y. Huang and X. Duan, ACS Appl. Mater. Interfaces, 2016, 8, 26769-26774.

3. W. Zhong-Li, X. Dan, X. Ji-Jing and Z. Xin-Bo, Cheminform, 2014, 43, 7746-7786.

4. W. D. N. Jia, M. Tang and T. F. Jaramillo, Energy Environ. Sci., 2014, 7, 2017-2024.

5. J. Stacy, Y. N. Regmi, B. Leonard and M. Fan, Renewable Sustainable Energy Rev., 2017, 69, 401-414.

6. C. Zhu, H. Li, S. Fu, D. Du and Y. Lin, Chem. Soc. Rev., 2016, 45, 517-531.

7. N. Yao, L. Li and W. Zidong, Chem. Soc. Rev., 2015, 46, 2168-2201.

8. W. Xia, A. Mahmood, Z. Liang, R. Zou and S. Guo, Angew. Chem., Int. Ed., 2016, 55, 26502676.

9. D. Ashok Kumar, R. K. Layek, K. Nam Hoon, J. Daeseung and L. Joong Hee, Nanoscale, 2014, 6, 10657-10665.

10. Y. J. Feng, T. He and N. Alonso-Vante, Fuel Cells, 2010, 10, 77-83. 
11. X. Li, Y. Fang, X. Lin, T. Min, X. An, F. Yan, L. Rong, J. Jin and J. Ma, J. Mater. Chem. A, 2015, 3, 17392-17402.

12. M. S. Faber, D. Rafal, M. A. Lukowski, N. S. Kaiser, D. Qi and J. Song, J. Am. Chem. Soc., 2014, 136, 10053-10061.

13. Y. Xue, S. Sun, W. Qin, Z. Dong and Z. Liu, J. Mater. Chem. A, 2018, 6, 24210-24215.

14. N. T. Suen, S. F. Hung, Q. Quan, N. Zhang, Y. J. Xu and H. M. Chen, Chem. Soc. Rev., 2017, 46, 337.

15. M. R. Gao, S. Liu, J. Jiang, C. H. Cui, W. T. Yao and S. H. Yu, J. Mater. Chem., 2010, 20, 9355-9361.

16. L. F. Zhang and C. Y. Zhang, Nanoscale, 2014, 6, 1782-1789.

17. G. Min-Rui, X. Yun-Fei, J. Jun, Z. Ya-Rong and Y. Shu-Hong, J. Am. Chem. Soc., 2012, 134, 2930-2933.

18. H. Li, G. Dong and C. Xuan, Electrochim. Acta, 2014, 138, 232-239.

19. Q. Wang, F. Chen, L. Guo, T. Jin, H. Liu, X. Wang, X. Gong and Y. Liu, J. Mater. Chem. A, 2019, 7, 16122-16135.

20. J. Wang, F. Chen, Y. Jin, L. Guo, X. Gong, X. Wang and R. L. Johnston, Nanoscale, 2019, 11, 14174-14185.

21. L. Guo, F. Chen, T. Jin, H. Liu, N. Zhang, Y. Jin, Q. Wang, Q. Tang and B. Pan, Nanoscale, 2020, 12, 3469-3481.

22. Q. Tang, F. Chen, T. Jin, L. Guo, Q. Wang and H. Liu, J. Mater. Chem. A, 2019, 7, 2299623007.

23. Q. Liu, J. Jin and J. Zhang, ACS Appl. Mater. Interfaces, 2013, 5, 5002-5008 .

24. R. Wu, Y. Xue, L. Bo, K. Zhou, J. Wei and S. H. Chan, J. Power Sources, 2016, 330, 132139.

25. S. M. Unni, J. M. Mora-Hernandez, S. Kurungot and N. Alonso-Vante, Chemelectrochem, 2015, 2, 1339-1345.

26. M. R. Benzigar, S. N. Talapaneni, S. Joseph, K. Ramadass, G. Singh, J. Scaranto, U. Ravon, K. Al-Bahily and A. Vinu, Chem. Soc. Rev., 2018, 47, 2680-2721.

27. I. Yoshikazu, Q. H.-J., F. Takeshi, T. Yoichi, T. Katsumi and C. Mingwei, Adv. Mater., 2014, 26, 4145-4150.

28. A. Shah, A. Zahid, H. Subhan, A. Munir and M. Akbar, Sustainable Energy Fuels, 2018, 2, 1398-1429.

29. Y. Z. Chen, C. Wang, Z. Y. Wu, Y. Xiong, Q. Xu, S. H. Yu and H. L. Jiang, Adv. Mater., 2015, 27, 5010-5016 . 
30. S. Gadipelli, T. Zhao, S. A. Shevlin and Z. Guo, Energy Environ. Sci., 2016, 9, 1661-1667 .

31. O. K. Michael and O. M. Yaghi, Chem. Rev., 2012, 112, 675-702.

32. S. Norbert and B. Shyam, Cheminform, 2012, 43, 933-969.

33. L. Zou and H. C. Zhou, Adv. Mater., 2007, 17, 3154-3160.

34. G. Zhang, R. Chenitz, M. Lefèvre, S. Sun and J. P. Dodelet, Nano Energy, 2016, 29, 111-125.

35. A. Morozan and F. Jaouen, Energy Environ. Sci., 2012, 5, 9269-9290.

36. X. Liu, T. Sun, J. Hu and S. Wang, J. Mater. Chem. A, 2016, 4, 3584-3616.

37. B. Chen, Z. Yang, Y. Zhu and Y. Xia, J. Mater. Chem. A, 2014, 2, 16811-16831.

38. L. Shang, H. Yu, X. Huang, T. Bian, R. Shi, Y. Zhao, G. I. Waterhouse, L. Z. Wu, C. H. Tung and T. Zhang, Adv. Mater., 2015, 28, 1668-1674

39. P. Yin, T. Yao, Y. Wu, L. Zheng, Y. Lin, W. Liu, H. Ju, J. Zhu, X. Hong and Z. Deng, Angew. Chem., 2016, 128, 10958-10963.

40. D. Wang, G. Fang, X. Tong, J. Ma and G. Geng, J. Power Sources, 2016, 307, 401-409.

41. J. Zhang, L. Yu and X. W. D. Lou, Nano Res., 2017, 10, 4298-4304 


\title{
CoSe2/Co nanoheteroparticles
}

embedded in Co, Nco-doped carbon nanopolyhedra/nanotubes as anefficient oxygen bifunctional electrocatalyst for pÿZn air batteries

\author{
Zou, Jizhao
}

Royal Society of Chemistry

Zou J, Luo Q, Wu H, et al., (2020) CoSe2/Co nanoheteroparticles embedded in Co, Nco-doped pÿcarbon nanopolyhedra/nanotubes as anefficient oxygen bifunctional electrocatalyst for Zn air batteries. Sustainable Energy and Fuels, Volume 4, Issue 9, September 2020, pp. 4722-4732 https://doi.org/10.1039/D0SE00019A Downloaded from Cranfield Library Services E-Repository 